\title{
TRASCENDER LA VIOLENCIA DE GÉNERO DESDE EL RECONOCIMIENTO ÉTICO: UN DIÁLOGO ENTRE LA FILOSOFÍA Y LA EMPIRIA EN CONTEXTOS MIGRATORIOS
}

\author{
The Ethical Recognition to transcend gender: A philosophical - empirical dialogue in \\ migratory contexts
}

\author{
Dora Elvira García-González* \\ Alethia Fernández de la Reguera Ahedo**
}

\begin{abstract}
RESUMEN
A partir del diálogo interdisciplinario entre las acepciones filosóficas de la violencia estructural y cultural y los resultados de un estudio sociológico de corte cualitativo sobre la violencia doméstica en contextos migratorios, este artículo muestra de manera reflexiva el funcionamiento del entramado entre cultura y la violencia por motivos de género, así como los mecanismos de poder que las sustentan y la posibilidad de revertir dichas estructuras. Mediante la utilización de los conceptos de violencia cultural, violencia estructural y reconocimiento ético, exploramos las posibilidades reales para revertir estas formas de violencia contra las mujeres. La violencia no es un estado inamovible, por lo que se requiere construir una prospectiva que nos permita vivir de una manera más humana. Las formas de violencia tanto explícitas como estructurales y culturales, legitimadas y justificadas en nuestro ámbito vital, han de ser rechazadas críticamente y trascendidas mediante un recurso importante: el reconocimiento ético.
\end{abstract}

Palabras clave: violencia de género, violencia estructural, violencia cultural, reconocimiento ético, migración.

\footnotetext{
* Directora de Investigación de la Escuela de Humanidades y Educación del Tecnológico de Monterrey. Ciudad de México, México. Correo electrónico: dora.garcia@itesm.mx

** Investigadora del Centro de Investigaciones y Estudios de Género de la Universidad Nacional Autónoma de México. Ciudad de México, México. Correo electrónico: alethia_reguera@cieg.unam.mx

Artículo recibido el 24 de mayo de 2016. Aceptado el 24 de abril de 2017.
} 


\begin{abstract}
Based in an interdisciplinary dialogue between philosophical conceptions on structural and cultural violence, and a qualitative study on domestic violence in migration contexts, this article points out the relationship between culture and violence against women, its power mechanisms, and the possibilities to revert them. The concepts of structural violence, cultural violence and ethical recognition, are essential for the analysis on the reversal of violence against women. The non- fixed state of violence demands the creation of a more humane way of living; therefore, all types of legitimized and justified violence (explicit, structural and cultural) in our lives must be critically rejected and surpassed by means of an infallible resource: ethical recognition.
\end{abstract}

Keywords: gender-based violence, structural violence, cultural violence, ethical recognition, migration.

"Nadie consagrado a pensar sobre la historia y la política puede permanecer ignorante del enorme papel que la violencia ha desempeñado siempre en los asuntos

humanos".

Hannah Arendt ${ }^{1}$.

\title{
A MODO DE INTRODUCCIÓN: LA VIOLENCIA COMO PARTE DE LAS RELACIONES HUMANAS
}

Las dramáticas historias, tanto en los espacios públicos como privados, que narran hechos violentos cuyas víctimas son generalmente mujeres, dan cuenta de las estructuras de poder que han predominado en los espacios sociales. Tales estructuras avalan y justifican las diversas formas de violencia en contra de las mujeres, sobre todo y de manera explícita, en el espacio doméstico ${ }^{2}$. Históricamente en este entorno privado las acciones de los varones no se cuestionan, dado que uno de los supuestos básicos se funda en que son ellos quienes detentan la autoridad en estos espacios.

El sustento empírico que avala estas reflexiones se basa en un trabajo de campo de corte cualitativo realizado con mujeres oriundas del Estado de Tlaxcala con el fin de conocer cómo la experiencia migratoria impacta en los procesos de autonomía de mujeres extrabajadoras migrantes de retorno ${ }^{3}$. La selección de las

\footnotetext{
${ }^{1}$ Arendt, Hannah. "Sobre la violencia" en Crisis de la República, España, Editorial Taurus, 1998, p. 116.

${ }^{2}$ Los términos violencia doméstica y violencia de pareja se utilizan indistintamente para referirse a la violencia de los hombres contra las mujeres en el entorno de una convivencia del tipo conyugal. ${ }^{3}$ Entre octubre de 2012 y febrero de 2013 se reconstruyeron cinco historias de vida, a partir de entrevistas a profundidad con cinco mujeres extrabajadoras migrantes de retorno de Estados
} 
informantes ${ }^{4}$ se realizó a partir de un muestreo teórico con el fin de engrosar las categorías analíticas, sin perder la especificidad de cada caso. Para el análisis de las entrevistas se empleó la técnica de teoría fundamentada, con el fin de obtener hipótesis derivadas de los datos recopilados y analizados sistemáticamente. En este artículo se presentan algunas de las hipótesis que surgieron del análisis del tema de violencia de pareja en las entrevistas. Aunque la guía de entrevista no estuvo dirigida originalmente a trabajar el tema de violencia de pareja, esta surgió como una temática central en los relatos de las informantes. La experiencia en el campo evidenció la necesidad notable de las informantes por expresar y narrar sus experiencias de violencia doméstica.

En un esfuerzo por generar conocimiento a partir del diálogo entre algunas teorías sobre las violencias estructurales y culturales de corte filosófico y un trabajo de campo sociológico, buscamos con este texto dos objetivos: el primero es hacer una aportación a las diversas formas en que la violencia doméstica se posiciona como consecuencia y, a su vez, como causa de la desigualdad de género. El segundo objetivo se sitúa en la utilización de los conceptos violencia cultural, estructural y reconocimiento ético, como categorías analíticas para explorar las posibilidades reales de revertir estas formas de violencia contra las mujeres.

Una de las aportaciones teórico-metodológicas del texto corresponde a un análisis de orden social, basado en la violencia estructural y cultural, desde un enfoque interdisciplinario. Ambos conceptos se desarrollan como categorías analíticas desde la sociología y la filosofía, para dar cuenta no solo de las causas de la violencia, sino del entramado entre la cultura y las diversas formas de violencia por motivos de género, así como de los mecanismos de poder que las sustentan y la posibilidad de superar dichas estructuras 5 .

Unidos, en el municipio de San Francisco Tetlanohcan, en el Estado de Tlaxcala. Este municipio fue reconocido en 1995 como municipio urbano nahua. Sin embargo la infraestructura y el estilo de vida es semi-rural en proceso de urbanización. De acuerdo al INEGI, el Censo 2010 reporta que la población de este municipio es de 9,880 habitantes distribuidos en 2,210 hogares con un promedio de 4.5 habitantes por hogar, de los cuales el 20.9\% tiene jefatura femenina. Las ciudades más recurrentes a las que se migra son: Nueva York (NY) y New Heaven (CT).

${ }^{4} \mathrm{Al}$ momento de las entrevistas las informantes tenían entre 25 y 45 años, estaban en pareja o separadas, eran madres de al menos dos hijos, su nivel de escolaridad oscilaba entre primaria y preparatoria, y contaban con la experiencia de haber sido migrantes en Estados Unidos.

${ }^{5}$ El texto es resultado de la articulación de la teoría con los datos que emergieron del trabajo de campo. En todo momento el análisis busca articular lo individual con lo colectivo; es decir, mostrar cómo a partir de un relato, un sujeto universaliza lo social estructural al reproducirse como su singularida(ver en: Reséndiz García, Ramón. "Biografía proceso y nudos teórico-metodológicos". Observar, escuchar y comprender: sobre la tradición cualitativa en la investigación social. En Tarres, María Luisa (Ed.). México: El Colegio de México, 2008, pp. 135-170. Las historias de vida nos permitieron conocer un orden social a partir de la especificidad del relato individual. 
Las narraciones de las mujeres sobre sus experiencias de violencia se relacionan con situaciones en las que supuestamente atentan contra el poder de sus parejas y, como consecuencia de esta "osadía", aparece el merecimiento de una sanción. Este es el primer tema que se pretende resaltar en este escrito, dado que la violencia de la pareja se disfraza de afecto -como se evidencia en los celos- y se legitima como disciplina. El poder incuestionable del varón tiene consecuencias que representan el mayor obstáculo en los procesos de autonomía y construcción personal de las mujeres en el espacio analizado. La segunda temática expone las condiciones que favorecieron la separación de una pareja violenta a partir de las experiencias que vivieron las mujeres entrevistadas durante su migración a Estados Unidos.

El análisis de las dos temáticas muestra por un lado, la reproducción de un discurso que establece que el comportamiento propio de las mujeres no debe provocar que la ira se apodere de los varones y se vuelvan violentos. Por otro lado, dicho análisis confronta el supuesto de la naturalización de la violencia sobre todo en los varones- como algo inherente y en todo caso inevitable. Los testimonios presentan situaciones que implican el uso de la violencia legitimada tradicionalmente como una exigencia para la construcción social, al anclarse en el centro simbólico de las sociedades y las culturas ${ }^{6}$. Así, la guerra es pensada como inherente y propia del ser humano y de la sociedad ${ }^{7}$.

No podemos asegurar que la violencia es una determinación inserta en la genética humana ${ }^{8}$ dado que esto supone un riesgo perverso situado en la naturalización de tal violencia. Con ello, se dificulta el convencimiento de luchar por cambiar ese estado de cosas. El enorme peligro de defender la violencia como parte esencial de lo humano es que las acciones violentas se justifican como algo natural y, siguiendo esta lógica, la violencia se ha ubicado en el centro simbólico de las sociedades tradicionales.

El presente texto propone que la superación de la violencia se sustenta en el pensamiento ético, que implica el respeto a las personas por su dignidad y mediante el reconocimiento y una responsabilidad solidaria ${ }^{9}$ a partir de los testimonios

\footnotetext{
${ }^{6}$ Ver en: Girard, René, La violencia y lo sagrado, Barcelona, Editorial Anagrama, 2005.

${ }^{7}$ Clastres, Pierre, Arqueología de la violencia:la guerra en las sociedades primitivas, México: Fondo de Cultura Económica, 2004.

${ }^{8}$ En este punto las discusiones son grandes. Hay quienes sostienen que por naturaleza somos agresivos, sin embargo es preciso discernir entre la agresividad y la violencia. La racionalización de la especie humana ha llevado a sostener que la violencia es menor hoy día que en tiempos pasados (hace seis siglos, por ejemplo). Ver en: Muchembled, Robert, Una historia de la violencia del final de la edad media a la actualidad. Madrid, Paidós, 2010; y, Torres, Mauro, ;La guerra!, enfermedad congénita de la humanidad, Madrid: Biblioteca Nueva, 2012.

${ }^{9}$ Cortina Orts, Adela, 1995.
} 
obtenidos en contextos migratorios. En el primer apartado describimos -a partir de una de las hipótesis que surgieron en las entrevistas- la violencia disfrazada de afecto y disciplina por parte del varón como uno de los pilares de la vida conyugal. Asimismo, se muestra cómo opera el entretejido de las violencias estructural, cultural y directa en la relación de pareja. En el segundo apartado reflexionamos, a partir de las especificidades en que se presenta la violencia -directa, estructural y cultural-, sobre su relación con situaciones de sujeción y desvalorización. A su vez, estas dimensiones se vinculan con una consecuente ausencia de reconocimiento ético de las mujeres, que tiene efectos en las formas de percibirse a sí mismas y en las formas de enfrentarse al mundo, en donde son lastimadas sistemáticamente. En el tercer apartado se ahonda en la comprensión de la relevancia acerca del reconocimiento para la construcción de la identidad, -así como sus contrapartes: falsos reconocimientos y reconocimientos funcionales-. La vinculación del reconocimiento con la violencia es fundamental, porque la falta o falsedad del primero, propicia la desvalorizacion de las personas, y por ende estimula la violencia. Así, con Galtung, sostenemos que la violencia se entiende como aquellas "afrentas evitables a las necesidades humanas básicas y más globalmente, contra la vida" ${ }^{10}$. Son formas de violencia que al estar enraizadas ya no se visualizan como tales porque se normalizan, pero sus consecuencias son destructivas para esas mujeres. En el cuarto apartado se abren alternativas para pensar en un nuevo comienzo a partir de la posibilidad de separación de la pareja violenta en contextos migratorios. El recurso corresponde al principio arendtiano de la acción, desde él se potencia la libertad y la generación de un cambio para las mujeres sojuzgadas; y finalmente se presentan las conclusiones.

\section{NATURALIZACIÓN DE LA VIOLENCIA EN EL ESPACIO DOMÉSTICO: EL TRIÁNGULO DE LA VIOLENCIA ESTRUCTURAL, CULTURAL Y DIRECTA EN LAS MUJERES}

Una de las tres formas de violencia, la violencia estructural, se presenta en las instituciones sociales y no es perceptible, sino que se asienta en nuestras sociedades de manera silenciosa, ubicándose en las estructuras, en los imaginarios colectivos y en las formas de conducta tradicionales. Los maltratos que narran las mujeres por parte de sus parejas constituyen, no solo la evidencia paradigmática de la violencia estructural, sino de la operatividad de la violencia cultural que subyace a la primera y funge como justificatoria de tales comportamientos.

\footnotetext{
${ }^{10} 2010$.
} 


\section{De acuerdo a Christian Retamal ${ }^{11}$ :}

La dialéctica de la Ilustración -y su dialéctica utópica derivada- tiene que objetivarse en las relaciones de poder que atraviesan lo social. Evidentemente aquello que denominamos como poder no existe como una entidad, una sustancia, sino que ante todo es una capacidad de sujetos concretos que están en un campo de tensiones y enfrentamientos, con intereses a veces divergentes o convergentes y que se influyen mutuamente (2008:168).

Las formas violentas contra las mujeres en espacios domésticos corresponden a un orden de género que reproduce una representación de la masculinidad relacionada a la capacidad de los varones de disciplinar a las mujeres y a sus familias. Esta representación social arraigada y difundida, entre hombres y mujeres, se posiciona como norma social de la vida conyugal. Es el cimiento lógico de la reificación de la violencia, entretejida con el afecto. Los testimonios muestran una relación entre la práctica de disciplina como forma de violencia y la afectividad.

Y luego a veces me dice el esposo de mi tía: “Te quiere mucho tu marido". Y le digo: "Sí me quiere mucho pero chinga". Y se ríe y me dice: "No es cierto, sí te quiere mucho tu marido (Marcela, 37 ańos, trabajadora migrante por dos años).

Esta práctica social de afectividad y poder es muy perversa, ya que la dimensión emocional facilita que la violencia se prolongue en el tiempo con una carga simbólica para las mujeres. Es decir, "si te quiere te pega" o "si es celoso es porque te quiere" suelen ser mensajes muy arraigados en la sociedad para justificar las asimetrías de poder al interior de la vida conyugal y la violencia en todas sus dimensiones. En este caso Marcela, quien fue trabajadora migrante en Estados Unidos por dos años, ha sufrido violencia a lo largo de los 18 años de su matrimonio; la misma que se ha acrecentado en distintas transiciones de su trayectoria familiar, tal como en su segundo embarazo y con la migración. Cuando Marcela ha intentado buscar apoyo en sus redes familiares para salir de la violencia, las respuestas que ha recibido van desde "¿qué le hiciste a tu marido para que te pegara?" hasta "te quiere mucho tu marido".

Al considerarse como autoridad, los varones detentan no solo poder emocional, sino también material y social. Esta concepción es el origen de importantes desigualdades en términos de división del trabajo (tanto en los mercados laborales como en las ocupaciones y esfuerzos por la crianza y reproducción); en el

\footnotetext{
11 2008, p.168.
} 
incremento de la brecha que favorece el acceso de los hombres a recursos materiales, sociales, culturales y simbólicos. Su autoridad -como figura que disciplina-, deviene de premisas fundacionales culturalmente arraigadas en el orden social; transmitidas desde la infancia, afianzan la certeza sobre el derecho de los hombres a controlar la vida de las mujeres ${ }^{12}$; de nuevo como una carga simbólica que suele acompañar a las mujeres a lo largo de toda su vida matrimonial.

Porque nos platicaba mi mamá: “Te vas a casar, te vas a ir. ¿Ya lo pensaste bien? Porque eso es para toda la vida. No es un trapo viejo que dices hoy me lo pongo y mańana ya no me gusta, lo voy a aventar. Aquí llevamos la generación de nuestros abuelitos que nos enseñaban que si nos vamos a casar es porque ya lo pensamos bien, es porque nos vamos a aguantar todo lo que pasemos (Marcela, 37 años, trabajadora migrante por dos ańos).

La perspectiva de Marcela muestra cómo se puede cristalizar de manera patente la violencia estructural -que se encuentra en las estructuras sociales-con la cultural- ubicada en las culturas, en los hábitos y costumbres-, y la directa, las cuales constituyen "afrentas evitables a las necesidades humanas"13. La dimensión afectiva puede justificar la violencia de pareja tras el disfraz del amor: las mujeres pueden interpretar la violencia como preocupación por parte de los varones por encaminarlas, como una muestra de cariño. Además, la creencia sobre la centralidad del valor de la familia, como institución articuladora de la sociedad, apuntala y reproduce la violencia desde las fases más estructurales de una comunidad.

Por su parte, la violencia cultural manifestada como violencia emocional, la estructural mediante la violencia económica, se asumen como un aspecto más del sacrificio que las mujeres hacen como parte de su vida conyugal. En las entrevistas se observa que el maltrato emocional opera como descalificación, humillación, desconfianza y denigración constante en el tiempo. El maltrato económico genera y refuerza la desconfianza en las mujeres como personas capaces para encargarse económicamente de sí mismas y de su familia; invisibiliza su trabajo y perpetúa la precariedad económica de su vida, aceptando la figura de la pareja como autoridad incuestionable.

Yo nada más me dedicaba a lo mismo, a limpiar, me tocaba lavar el piso y nada más no trabajaba. Él tampoco quería que yo trabajara. Me decía: “¿Cómo vas a trabajar y los niños? Quédate y yo trabajo”. Pero yo no se cuál era su verdadera intención de que yo no saliera. Entonces pues yo seguía, lavaba nada más el piso y ya (Catalina, 45 años, trabajadora migrante por once años).

\footnotetext{
${ }^{12}$ Rowland-Serdar, Barbara, and Peregrine, Schwartz-Shea, "Empowering Women: Self, Autonomy, and Responsibility", The Western Political Quarterly, 44/3 (1991): 605-624.

${ }^{13}$ Galtung, Johan, 2003, p. 265.
} 
En los testimonios fue común observar que la autonomía económica es un factor relevante para identificar los periodos en las trayectorias de vida donde las mujeres experimentan más violencia por parte de sus parejas; ya sea momentos en que las mujeres carecen de esta autonomía, es decir no tienen un ingreso o no controlan el ingreso que generan, o momentos en donde comienzan a ser coproveedoras como suele suceder con el inicio de la migración. Este hallazgo lanza una hipótesis hacia el análisis de las rupturas y las continuidades en los arreglos tradicionales de la división sexual del trabajo -donde ellas son cuidadoras en el ámbito privado y ellos proveedores en el público- como elemento central del abordaje de la violencia de género, particularmente la violencia doméstica.

Bajo estos presupuestos, las relaciones de pareja se implican en un escenario en que la violencia presente se mantiene y el dominio e indignación se afianzan, al perpetrarse la destrucción de quienes están sometidos, principalmente y en este caso, las mujeres. El carácter de estas dinámicas implica que la búsqueda de la igualdad garantiza, en cierta forma, la superación de la violencia que significa asimismo superación de la indignación.

\section{Efectos de las violencias estructural y cultural: sujeción y desvalorización}

Los testimonios dan cuenta de la dificultad del proceso que sobrellevan las mujeres para cuestionar estas violencias entretejidas en formas culturales profundamente destructoras de la dignidad. La violencia desde el rol disciplinador del varón, como parte del matrimonio, avala la sujeción de las mujeres, su minusvalía como agentes y la cancelación de su libertad. La falta de reconocimiento así como también la operatividad de un reconocimiento manipulado moldean identidades falsas, de modo que el falso reconocimiento se convierte en una forma de opresión que, desde una percepción deformada, adulterada y reducida de las mujeres, profundiza y afianza la sujeción y el dominio. Al existir tal reconocimiento desfigurado, la construcción de la identidad resulta ser igualmente falsa como lo ilustra el caso de Marcela; "por ello, algunas feministas han sostenido que las mujeres en las sociedades patriarcales fueron inducidas a adoptar una imagen despectiva de sí mismas. Internalizaron una imagen de su propia inferioridad [...] Su propia auto-depreciación se transforma en uno de los instrumentos más poderosos de su propia opresión"14.

A veces igual me pregunto, cuando él (su esposo) habla de separación siento feo, porque una pues aparentemente está sola, pero yo siento feo; no sé, sigo estando como si no existiera (Marcela, 37 años, trabajadora migrante por dos años).

\footnotetext{
${ }_{14}$ Taylor, Charles, 1993 , pp. 43-44.
} 
En los casos estudiados, la experiencia migratoria generó oportunidades para que las mujeres reflexionaran sobre ese falso reconocimiento sobre ellas mismas. Es importante destacar que dos elementos mediadores entre el falso reconocimiento y la capacidad auto-reflexiva fueron la posibilidad de crear nuevos arreglos en la división sexual del trabajo y ser generadoras y emisoras de remesas. Las mujeres migrantes entrevistadas eran co-proveedoras en Estados Unidos, generadoras de remesas quienes en su mayoría compartían la vivienda con otras personas (familiares, conocidos o desconocidos), por lo que las tareas domésticas (de limpieza y preparación de alimentos) se distribuían de forma equitativa o menos desigual tanto con su pareja como con los demás integrantes del hogar. Esto generó un cambio importante en el uso del tiempo de las mujeres; ya que muchas de ellas experimentaron por primera vez el tiempo libre y con ello la posibilidad de realizar otras actividades (por ejemplo caminar o convivir con compañeros/as de trabajo) que les permitieron expandir su capital social y cultural. Estas dos realidades de la migración -tener el reconocimiento como co-proveedoras a través de las remesas y experimentar nuevos arreglos de la división sexual del trabajo- generó procesos reflexivos de auto-reconocimiento y cuestionamiento del falso reconocimiento, en donde inclusive algunas mujeres dejaron a sus parejas temporalmente.

Esto muestra que la primerísima tarea de quienes pretenden liberarse de la opresión habrá de ser el desafanarse de esa identidad impuesta y destructiva; ese falso reconocimiento "no solo muestra de una fal ta del respeto debido. Puede infligir una herida dolorosa, que causa a sus víctimas un mutilador odio a sí mismas" ${ }^{15}$. El reconocimiento constituye una categoría ética obligada y no es de ninguna manera una cortesía; es una necesidad humana vital. No podemos seguir pensando que la única forma de movilizar a la gente es mediante el miedo, este es "un constitutivo de la subjetividad actual" ${ }^{16}$ que contiene una fuerte dosis de violencia, mostrándose bajo diversas formas imaginables, oscuras e incomprensibles ${ }^{17}$ que, al legitimarse en el entramado estructural de las sociedades, se convierte en violencia cultural y en violencia simbólica.

Dicha violencia simbólica apuntada por Pierre Bourdieu como "la violencia que arranca sumisiones que no se perciben como tales, apoyándose en

\footnotetext{
${ }^{15}$ Ibid.

${ }^{16}$ Ibid.

${ }^{17}$ La reconstrucción de la violencia divina de Benjamin (Benjamin, Walter, Crítica de la violencia, Madrid, Biblioteca Nueva, 2010) ha sido realizada por Bernstein (Bernstein, Richard, El abuso del mal: la corrupción de la politica y la religión desde el 11/9, Buenos Aires, Katz, 2006); Honeth (Honneth, Axel, Reconocimiento y menosprecio sobre la fundamentación normativa de una teoría social, Buenos Aires, Katz, 2009); Zizek (Zizek, Slavoj, Violence: Six Sideways Reflections, New York: Picador, 2008) y Butler (Butler, Judith, Gender Trouble: Feminism and the Subversion of Identity, New York, Routledge, 1990).
} 
unas "expectativas colectivas» en unas creencias socialmente inculcadas"18; lo que significa que esta violencia no se observa como tal porque se apoya en creencias que son infundidas y grabadas en el seno de la sociedad, y con ello se crean relaciones flagrantes de dominación y de sumisión. La violencia simbólica es una violencia inadvertida que hace que parezca natural y por ello se mantiene en el silencio y en la invisibilidad como parte de la violencia cultural ${ }^{19}$.

Está bien te lo voy a decir (el esposo a ella), ya no puedo más, sí tengo otra, pero pues no es igual que tú como mi esposa y ella nada más para pasar el rato; cuando tú vengas yo la dejo y ya". Y le digo: "Ay sí qué fácil, la dejo y ya, siento que no va a ser igual, mira si tú eres feliz al lado de esa persona, has tu vida, yo me hago a un lado y si tú eres feliz y sientes que lo vas a hacer con ella, adelante". Y entonces hablé con mi mamá porque ella estaba al lado de mi esposo; mi mamá decía que yo tuve la culpa por haberme ido. Y de hecho ella ya no quería hablar conmigo (Marcela, 37 años, migrante por dos años).

En este caso se observa una práctica común de violencia simbólica instaurada en sociedades muy tradicionales, donde se asume que los hombres tienen mayor libertad para establecer relaciones fuera del matrimonio, e inclusive que cuando se presenta una infidelidad se considera consecuencia de una falta de la mujer; es decir, hay un mandato de género arraigado que responsabiliza a las mujeres de la relación de pareja. Este testimonio muestra el contexto en que se dio la negociación para regresar con la pareja después de un año de separación. Marcela regresó con él a pesar de saber que él tenía una relación sentimental con otra persona; lo que se explica por un lado debido al poco apoyo que encontró por parte de su familia y por otro lado, a que asumió la infidelidad como una práctica cotidiana de su pareja. Ambas explicaciones son ejemplos sobre cómo opera la violencia simbólica (en este caso con la tolerancia a la infidelidad) al estructurar los esquemas de pensamiento de los dominados a partir del pensamiento del dominador.

Los testimonios muestran como elemento común el hecho de que las mujeres sean consideradas las responsables del funcionamiento de la relación de pareja $^{20}$. Cuando se presentaron los problemas normalmente las mujeres aparecieron como responsables. Las narraciones de las mujeres se concentraron regularmente en identificar qué hicieron mal, o en demostrar su inocencia, en lugar de cuestionar la autoridad del hombre. Su autoconcepto suele llevarlas desde las disposiciones inconscientes que plantea Bourdieu (2000) a aceptar ser sujetas de agresión. La sumisión consensuada de las dominadas se mantiene a través de una hegemonía

\footnotetext{
${ }^{18}$ Bourdieu, Pierre, Razones prácticas: sobre la teoría de la acción, Barcelona, Anagrama, 1999, p. 173.

${ }^{19}$ Bourdieu, Pierre, La Dominación Masculina. Barcelona: Editorial Anagrama, 2000, p. 51.

${ }^{20}$ Rowland-Serdar, op. cit.
} 
perpetuada por los aparatos ideológicos de la sociedad: la educación, la religión, la ley y los medios de comunicación, principalmente ${ }^{21}$. Tal y como lo muestra el siguiente testimonio, todos estos atuendos ideológicos pretenden mantener y legitimar las relaciones asimétricas de poder y los procesos de exclusión y de dominación.

Nos fuimos y ya salgo embarazada como a los dos años. Pero ya los problemas eran fuertes porque yo no sé si es por mi forma de ser o no se... pero empecé a tener problemas otra vez por lo mismo. Él trabajaba en un restaurante como mesero. Pero de ahí como miraba que no nos alcanzaba, porque ya era un niño y luego embarazada del otro, pero sí me pegaba. Un poquito antes de salir embarazada del niño me pegaba mucho pero por lo mismo por los chismes que le decían de mí y yo no sabía porqué (Catalina, 45 años, trabajadora migrante por once años).

\section{EN BUSCA DEL RECONOCIMIENTO ÉTICO DE LAS MUJERES EN SITUACIÓN DE VIOLENCIA}

Como se afirmó anteriormente, el reconocimiento es una categoría muy socorrida en las teorías éticas y políticas de vena principalmente hegeliana, entre ellas la ya citada perpectiva de Charles Taylor (1993). Asimismo, Paul Ricoeur ${ }^{22}$ sostiene que todas las personas queremos ser tomadas en cuenta, ser respetadas y reconocidas. Nuestra concepción apunta hacia el respeto y consideración de la dignidad como personas, no al reconocimiento meramente instrumental o funcional. A través de las formas de reconocimiento se viabiliza la superación de la violencia; por ello, la búsqueda de tal reconocimiento pretende la justicia para todas las mujeres. En este sentido "el progreso moral nace de la lucha por el reconocimiento" ${ }^{23}$. Debemos procurar romper con la homogeneización y la prevalencia de un pensamiento único que pretende un igualitarismo, pero no necesariamente la igualdad. Por ello se busca la diferencia ${ }^{24}$ y se pretenden interacciones sociales con implicaciones y contenidos morales en la intersubjetividad y la búsqueda de una lucha por el reconocimiento. Así, podemos apuntar que las experiencias de negación del reconocimiento y del menosprecio a los individuos hieren la subjetividad de tal modo, que tienen un papel esencial en la historia del desarrollo de las estructuras normativas morales, jurídicas y políticas. La experiencia del menosprecio puede influir en el origen de los conflictos sociales y muchos de estos se originan por la falta de reconocimiento

\footnotetext{
${ }^{21}$ Gramsci, Antonio, 1971.

${ }^{22}$ Ricoeur, Paul, 2005.

${ }^{23}$ Comins Mingol, Irene.

${ }^{24}$ Ricoeur, op. cit.
} 
intersubjetivo ${ }^{25}$ dado que, por el respeto y la apreciación valoral se hace posible que las mujeres tengan autoconfianza, autorrespeto y autoestima, y desde ahí impidan el maltrato y la disposición libre de su cuerpo.

Las modalidades del menosprecio dan pie a alternativas de reconocimiento, sea desde la aprobación emocional ${ }^{26}$, sobre los derechos de las mujeres reconocidas y este reconocimiento se extiende a todas las personas posibles expresando un reconocimiento solidario, fundamentado en la posibilidad de ponerse en el lugar de dichas mujeres, en el marco de la intersubjetividad de los afectos, los derechos y la valoración social.

El yo se encuentra en una red de relaciones con las demás personas, con el respeto a sus necesidades y con el esfuerzo mutuo por satisfacer tales necesidades. Dicha red refuerza el crecimiento y el desarrollo moral, cuestión que se vincula con el sujeto incardinado ${ }^{27}$ que, al reconocer al/la otro/a y su dignidad, propicia la superación de la violencia y el logro de la paz. Y por este camino consigue la cancelación, tanto del patriarcalismo autoritario, como de las lógicas de la guerra, fuertes inhibidoras de la preocupación por los/las otros/as. Esto contiene un ideal ético de responsabilidad con relación a los/las otros/as, en una lógica compasiva y de madurez en el marco de la justicia y del cuidado de las personas.

\section{SOBRE LA POSIBILIDAD DE UN NUEVO COMIENZO: LA ACCIÓN COMO PRINCIPIO DE LAS MUJERES EN CONTEXTOS MIGRATORIOS}

Iniciar de nuevo una vida para renunciar al maltrato y a aquellos vínculos lacerantes de la dignidad de las mujeres y de su existencia misma, implica una acción en la que se hace patente la libertad y la posibilidad del discurso. Contrariamente, a quienes se les cancelan estas capacidades, simplemente se constituyen como aquellas que no tienen derecho a nada ${ }^{28}$, ubicadas a la deriva, en una situación de dentro y fuera de la sociedad. Las relaciones generizadas ${ }^{29}$ se ejemplifican con nitidez en las experiencias narradas. Estas se legitiman y perpetúan gracias a ciertos "mitos prescriptivos", es decir a invenciones estereotípicas que han «naturalizado»

\footnotetext{
${ }^{25}$ Honneth, Axel, "Reconocimiento y obligación moral", Areté: Revista de Filosofía 9/2 (1997): 235-252.

${ }^{26}$ Honneth, Axel, La lucha por el reconocimiento, op. cit., p.117.

${ }^{27}$ Benhabib, Seyla, El Otro Generalizado, 1990, p.144.

${ }^{28}$ Es la situación a la que alude Arendt en su reconocido enunciado: "derecho a tener derechos" (ver en: Arendt, Hannah, Los origenes del Totalitarismo, Madrid, Alianza, 1987, p. 430).

${ }^{29}$ Butler, Judith, Gender Trouble: Feminism and the Subversion of Identity, New York, Routledge, 1990.
} 
la posición subalterna de las personas que son identificadas como mujeres ${ }^{30}$. Los rasgos que se atribuyen a las mujeres: pasividad, dependencia y fragilidad, afianzan la subordinación que se evidencia en una división sexual del trabajo que genera desigualdades en términos materiales, sociales y simbólicos,

Luego mi hija me dice: “'porqué regresaste con mi papá con todo lo que me cuentas?, yo ya no hubiera regresado, hubieras hecho tu vida". Y yo le digo: "no sé, como que siempre pienso ¿qué dirán? esa fulana de tal”. Hubo una vez, no tiene mucho, que sí me deprimí mucho y me sentí mal porque si una persona no está a gusto con uno y no se siente feliz ¿cómo va a estar uno viviendo? ¿para qué? Como que esa vez yo dije sí. Mi hija me dijo: "Déjalo, ponte a trabajar". Y entonces lo primero que me llegó fue la idea fue de que se acaba todo y yo me puedo ir, puedo trabajar y puedo sacarlos adelante, pero mi niño escuchó todo eso y lloraba mucho y me decía: "Mamá no lo dejes, yo no quiero separarme de mi papá (Marcela, 37 años, trabajadora migrante por dos años).

En este testimonio claramente se aprecia el peso que las representaciones sociales de las mujeres como personas dependientes y frágiles genera en la interpretación que el sujeto elabora sobre la acción social, en este caso en decidir separarse o no; se observa a través de la fuerza del estigma social frente a la separación. Cabe señalar que antes de este acontecimiento (que ocurrió en el retorno a México) hubo un intento de separación estando en Estados Unidos; sin embargo Marcela decidió regresar con él debido a que perdió la comunicación y el control sobre el cuidado de su hija quien vivía con los suegros en México. Al separarse, le prohibieron hablar con ella y no podía decidir sobre la forma en que se gastaban las remesas que enviaba destinadas a la manutención de la niña. Años más tarde, después del retorno a México fue más difícil la separación por varias razones: en primer lugar el miedo de su hijo pequeño a enfrentar un proceso así, en segundo lugar por el estigma social de ser una mujer separada, en tercer lugar el hecho de que ella no tenía un ingreso fijo, y finalmente debido a que su familia no la apoyaba.

A pesar de estas limitantes, en los testimonios se identifican puntos de inflexión en donde las mujeres consiguieron separarse de sus parejas violentas. En la mayoría de los casos la separación se facilitó por las condiciones positivas que generó la migración (nuevas redes de apoyo, nuevos arreglos de división del trabajo doméstico, capacidad para generar un ingreso reconocido mediante las remesas) y que facilitaron su camino hacia el reconocimiento ético.

\footnotetext{
${ }^{30}$ Biglia, Barbara, "Resignificando violencia (s), obra feminista en tres actos y un falso epílogo: maltratadores políticamente correctos". En Biglia, Barbara y San Martín, Conchi, Estado wonderbra: entretejiendo narraciones feministas sobre las violencias de género, Barcelona, Virus Editorial, 2007, p. 27.
} 
Él una vez hasta llegó tomado y me quiso golpear. Entonces digo: "Yo no me voy a dejar golpear otra vez por otro individuo". Entonces yo sí me dio mucho coraje y lo que hice lo mandé a la cárcel, lo deportaron. Y dije: "Jamás me voy a volver a dejar" (Catalina, 45 años, trabajadora migrante por once años).

El caso de Catalina muestra las posibilidades que presenta la migración cuando las mujeres se sienten protegidas por el Estado receptor para enfrentar la violencia. Es importante destacar que esto no es generalizable; por el contrario, es común que muchas mujeres por su calidad migratoria temen denunciar la violencia y terminar siendo deportadas. Pero para Catalina el contexto migratorio le facilitó denunciar la violencia con una llamada al 911 en Estados Unidos. Como consecuencia de ello, su pareja fue deportada; sin embargo meses después, él regresó y lo perdonó. Catalina explica que lo hizo por las dificultades del estigma social de ser una mujer migrante soltera, especialmente porque se sentía expuesta al acoso.

En tres de las cinco historias de vida, la migración representó la oportunidad para una separación, pero en la mayoría de los casos esta fue temporal, ciertos obstáculos materiales y simbólicos interfieren en la consolidación de su independencia. El desenlace de la separación es un proceso largo y complejo, difícilmente se pueden hacer clasificaciones de éxito o fracaso. En los casos estudiados, la separación definitiva se logró cuando la mujer tuvo acceso a un trabajo digno para la manutención de su familia, se apropió de algún bien (construyó su casa), y contó con redes de apoyo de calidad.

\begin{abstract}
Ahora sí yo no me voy a dejar, y el que quiera estar conmigo es porque va a estar conmigo, porque me quiere no por obligación. Y siempre se lo dije a él: No pienses que por el niño yo te voy a obligar a que estés conmigo. Si tú estás conmigo es porque quieres estar conmigo pero yo no te voy a obligar en ningún momento. (Catalina, 45 años, once años como trabajadora migrante).
\end{abstract}

Existen mujeres que actúan para seguir adelante con libertad y deciden comenzar de nuevo. La consecución de este nuevo comienzo se factibiliza particularmente a partir de: la potestad sobre el cuidado y la crianza de los hijos, la procuración de ingresos dignos y las redes sociales como entorno de apoyo. Estas condiciones facilitan el comienzo de nuevas posibilidades humanas, señaladas en el impulso del initum agustiniano, que da lugar a la acción y a la libertad ${ }^{31}$.

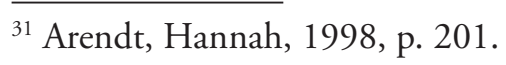




\section{CONCLUSIONES}

En suma, el presente texto pretende rubricar la posible y factible superación de las situaciones de violencia que vivimos cotidianamente. ¿Qué cabe esperar ante las situaciones narradas? La esperanza va relacionada con lo más propio de la condición humana: su capacidad de comenzar algo en el mundo, de orientarse y ubicarse en él; de esclarecer, a través de la confrontación y el diálogo, reconciliándose con un mundo en el que las situaciones de injusticia están presentes ${ }^{32}$. De ahí que "el resultado de la comprensión es el sentido, el sentido que nosotros mismos originamos en el proceso de nuestra vida, en tanto tratamos de reconciliarnos con lo que hacemos y padecemos" ${ }^{\text {"3 }}$.

Hemos defendido la comprensión sobre la violencia como estado no inamovible, porque es a partir de este posicionamiento que es factible construir una prospectiva para vivir humanamente, a pesar de la multiplicidad de conflictos que hemos de intentar sortear. Las formas de violencia -explícitas, estructurales o culturales- que se han legitimado y justificado en nuestro ámbito vital, deben ser rechazadas críticamente. Han de ser trascendidas mediante un recurso prácticamente infalible: el reconocimiento ético. A partir de este reconocimiento se hace plausible la proyección de mejores situaciones humanas, se vislumbra el alcance de una vida pacífica $^{34}$. Estos cursos alternativos se probabilizan con la promoción de escenarios de diálogo, mediante la reconciliación, la tolerancia y la solidaridad.

Para la reflexión sobre las posibilidades de superar la violencia y lograr la paz en la vida de las mujeres, es menester cimentarse en el acervo del pensamiento ético que sustenta la relevancia del respeto, la dignidad y la responsabilidad solidaria -dar a cada uno lo que le corresponde ${ }^{35}$-. Estos atributos, además de considerarse preponderantes, son operativos en cuanto se insertan y son constitutivos del entramado de símbolos que sustentan lo humano. A partir de una reflexión así planteada es posible contemplar opciones orientadas a la reconciliación social ${ }^{36}$, como horizonte para revertir las situaciones vividas. Esta es la instancia para la transformación de las violencias estructurales y culturales- contra las mujeres, para la adecuación de espacios públicos y privados inclusivos y conducentes a la realización de futuros deseables para ellas.

\footnotetext{
${ }^{32}$ García-González, Dora Elvira, 2005, p. 249.

${ }^{33}$ Arendt, Hannah, 1995, p. 30.

${ }^{34}$ Jiménez Bautista, Francisco, 2011, p. 117.

35 "Dar a cada uno lo que le corresponde" en el sentido de la definición de la justicia. Consideraciones que se fueron construyendo desde el pensamiento platónico y se consolidaron en el pensamiento jurídico latino representado por Ulpiano, como referente clásico.

${ }^{36}$ Johan Galtung es contundente en sus propuestas teóricas sobre el conflicto y la violencia, ofrece pistas para poder bregar en forma constructiva (ver en: Galtung, Johan, Tras la violencia, 3 : reconstrucción, reconciliación, resolución : afrontando los efectos visibles e invisibles de la guerra y la violencia, Bilbao, España, Bakeaz/Gernika Gogoratuz, 1998).
} 


\section{REFERENCIAS}

Arendt, Hannah. Los orígenes del totalitarismo. Madrid: Alianza, 1987.

Arendt, Hannah. De la historia a la acción. Barcelona: Paidós, 1995.

Arendt, Hannah. "Sobre la violencia” en Crisis de la República. España: Editorial Taurus, 1998.

Arendt, Hannah. Condición humana. Barcelona: Paidós, 1998.

Benhabib, Seyla. El otro generalizado y el otro concreto: la controversia KohlbergGilligan y la teoría feminista. Valencia: Edicions Alfons el Magnanim, 1990.

Benjamin, Walter. Crítica de la violencia. Madrid: Biblioteca Nueva, 2010.

Bernstein, Richard. El abuso del mal: la corrupción de la politica y la religión desde el 11/9. Buenos Aires: Katz, 2006.

Biglia, Barbara. "Resignificando violencia (s), obra feminista en tres actos y un falso epílogo: maltratadores políticamente correctos". Estado wonderbra: entretejiendo narraciones feministas sobre las violencias de género. En Biglia, Barbara y San Martín, Conchi. Barcelona: Virus Editorial, 2007.

Bourdieu, Pierre. Razones prácticas: sobre la teoría de la acción. Barcelona: Editorial Anagrama, 1999.

Bourdieu, Pierre. La dominación masculina. Barcelona: Editorial Anagrama, 2000.

Butler, Judith. Gender Trouble: Feminism and the Subversion of Identity. New York: Routledge, 1990.

Clastres, Pierre. Arqueología De La Violencia: la Guerra en las sociedades primitivas. México: Fondo de Cultura Económica, 2004.

Comins Mingol, Irene. "Cultura para la paz, hacia una búsqueda del reconocimiento", Fòrum de Recerca, 4 (1999): 1-8.

Cortina Orts, Adela. Razón comunicativa y responsabilidad solidaria. Salamanca: Sígueme, 1995. 
Galtung, Johan. Tras la violencia, 3 R: reconstrucción, reconciliación, resolución: afrontando los efectos visibles e invisibles de la guerra y la violencia. Bilbao: Bakeaz/Gernika Gogoratuz, 1998.

Galtung, Johan. Paz por medios pacificos: paz y conflicto, desarrollo y civilización. Bilbao: Bakeaz, 2003.

Galtung, Johan. Trascender y transformar una introducción al trabajo de conflictos. Ciudad de México: Editorial Quimera, 2010.

García-González, Dora Elvira. Del poder político al amor al mundo. México: Porrúa, 2005.

Girard, René. La Violencia y lo sagrado. Barcelona: Editorial Anagrama, 2005.

Gramsci, Antonio. Selections from the Prison Notebooks of Antonio Gramsci. London: Lawrence \& Wishart, 1971.

Honneth, Axel. La lucha por el reconocimiento por una gramática moral de los conflictos sociales. Barcelona: Crítica, 1997.

Honneth, Axel. "Reconocimiento y obligación moral", Areté: Revista de Filosofía 9/2 (1997): 235-252.

Honneth, Axel. Reconocimiento y menosprecio sobre la fundamentación normativa de una teoría social. Buenos Aires: Katz, 2009.

Jiménez Bautista, Francisco. Racionalidad pacifica: una introducción a los estudios para la paz. Madrid: Dykinson, 2011.

Muchembled, Robert. Una historia de la violencia del final de la Edad Media a la actualidad. Madrid: Paidós, 2010.

Reséndiz García, Ramón. "Biografía proceso y nudos teórico-metodológicos". Observar, escuchar y comprender: sobre la tradición cualitativa en la investigación social. En Tarres, Maria Luisa (Ed.). México: El Colegio de México, (2008):135-70.

Retamal, Christian. "Consideraciones sobre poder y dominación en la formación de la subjetividad moderna”, Universum, 23/2 (2008): 166-183. 
Ricoeur, Paul. Caminos del reconocimiento: tres estudios. Madrid: Editorial Trotta, 2005.

Rowland-Serdar, Barbara and Schwartz-Shea, Peregrine. "Empowering Women: Self, Autonomy, and Responsibility", The Western Political Quarterly, 44/3 (1991): 605-624.

Taylor, Charles. El Multiculturalismo y "La Politica del Reconocimiento". México: Fondo de Cultura Económica, 1993.

Torres, Mauro. ¡La guerra!, enfermedad congénita de la humanidad. Madrid: Biblioteca Nueva, 2012.

Zizek, Slavoj. Violence: Six Sideways Reflections. New York: Picador, 2008. 